\title{
A New Device used in Selective Withdrawal from Reservoirs and its Effectiveness Verified in Computational Fluid Dynamics
}

\author{
https://doi.org/10.3991/ijoe.v14i03.8421 \\ Lu Jinsuo( $\left.{ }^{\bowtie}\right)$, Zhang Wei, Wang Dengyu, Wang Xiaoyi \\ Xi'an University of Architecture and Technology, Xi'an, China \\ lujinsuodxauat.edu.cn
}

\begin{abstract}
Water intake with fixed height limits the application of selective withdrawal technology in a certain degree. This study proposes a technological idea to install baffles on water intake. Through the rotation of upper and lower baffle, poor water layer can be blocked. A Computational Fluid Dynamics (CFD) model for the upper baffle on water intake is constructed. The results show that the baffle installed on the upper part of orifice can reduce the withdrawal layer thickness and flow on the upper part of orifice centre. Thereby, the withdrawal flow on lower part can be indirectly increased. While, baffle length and inclining angle are the important factors to influence the withdrawal layer thickness and flow distribution. Therefore, the adjusting range of selective withdrawal can be economically enhanced by installing baffles on water intake.
\end{abstract}

Keywords—selective withdrawal, source water, baffle, FLUENT

\section{$1 \quad$ Introduction}

From late spring to early winter, obvious temperature stratification can be found on the reservoirs with water depth that exceeds $10 \mathrm{~m}$. The layers stratified include epilimnion, thermocline and hypolimnion. Thermocline isolates the mass transfer process between surface and hypolimnion. This isolation causes the anaerobic or anoxic condition of the bottom of reservoir, which leads to the high content of nutrient salt in sediment. Namely, dissolved oxygen deceases with the increase of water depth [1-7]; Moreover, with the rapid development of social economical development, in the surface layers of many reservoirs, water seasonal algae are in high incidence due to point source pollution, non-point source pollution and internal pollution [8-10]. The factors above deteriorate the inlet raw water quality of water plant and increase the difficulty and cost in purification.

Selective intake tower is a common water withdrawal technology of deep lake and reservoir water source. Usually, 3-5 water intakes are set on vertical direction of the tower. By choosing proper water intakes, varied water withdrawal requirements can be satisfied in different water levels and seasons [11-15]. However, the fixed height and the irreversibility of water withdrawal boundary of water intake still limit the 
access of obtaining quality raw water. At present, to solve the problem above, Gelda and Effler (2007) propose a multiple orifices water withdrawal technology to meet water demands [16]; In America and Japan, more prevalent techniques are adopted to improve the selective withdrawal characteristics of water intake tower. For example, temperature control device and water blocking devices are installed on a certain distance away from water intake tower to change the water quality distribution in reservoir, but such project amount is very huge and capital construction cost is high [1718]; According to the U.S. Bureau of Reclamation, the temperature control device of the Shasta dam in California costs $\$ 75$ million.

Although present renovation or new construction technology of selective intake tower can obtain expected water quality, their capital construction cost is very high. In this study, the baffles with certain length and can rotate up and down are installed on the upper and lower part of water intakes. Baffle and driving mechanism can be reassembled. And underwater installation can be realized by just fixing the device.

The device in the present study has been applied to the selective water intake tower of multi-layer water intakes or the withdrawal facilities of monolayer water intake that have been completed. However, in the researches and construction examples on existing selective withdrawal, the experiment and thought of adjusting selective withdrawal by baffle have not been reported. Therefore, there are certain difficulties in both field and laboratory experiments. But the successful case of hydraulic flow simulation by CFD offers some idea to validate the effect of this device [19]. Savage et al. (2004) had used FLUENT in their study and noted "that a robust 3D hydrodynamic model can effectively supplement experimental studies in understanding the complex flow field" in hydraulic structures [20]; Georgoulas et al. (2010) had used FLUENT to propose a 3D numerical model that simulates the dynamics and flow structure of turbidity current, through a multiphase flow approach [21]. Therefore, comparing with experiments, CFD simulation can verify the adjusting effect of baffle to selective withdrawal to some extent with a large amount of time and cost saved as well.

To verify the application effect of baffle in selective withdrawal, CFD software FLUENT is firstly formulated in this paper to simulate the water flow state of selective withdrawal of reservoir without baffle. The simulation objective in this study is the drinking water source of Heihe Jin-pen Reservoir in Xi'an in China. Then by comparing the corresponding data in the condition with baffle with those in the condition without baffle, the influences of baffle length and inclining angle to withdrawal layer thickness and flow distribution on upper and lower part of water intakes are analyzed to determine the proper baffle length.

\section{Method}

\subsection{Jin-pen reservoir and the new device-baffle}

Jin-pen reservoir is a large water conservancy project in comprehensive utilization. The selective water intake tower and water intake tunnel lie on the left bank of this reservoir. The selective water intake tower comprises three layers and three water 
intakes of size of $3.5 \mathrm{~m} \times 3.5 \mathrm{~m}$. The centre elevations of the three water intakes are $541.3 \mathrm{~m}, 554 \mathrm{~m}, 571 \mathrm{~m}$ respectively.

The baffle would be installed on the upper and lower part of water intakes. The structure of baffles in water intakes is shown in Fig. 1. By adjusting the angle between baffle and water intake, selective withdrawal limit in density stratification state can be adjusted.
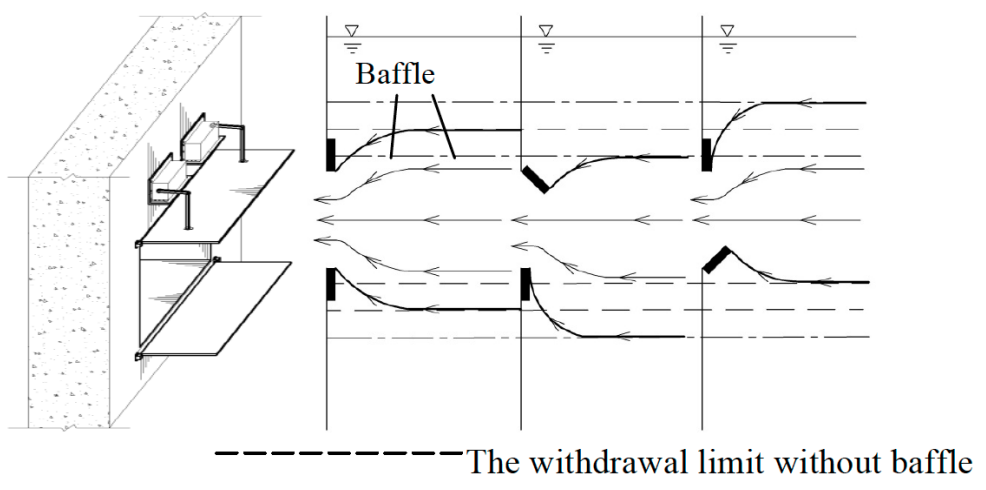

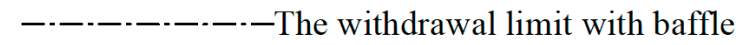

Fig. 1. Baffle schematic diagram

\subsection{Meshing and simulation method}

The water intake tower of Xi'an Jin-pen Reservoir is located near dam, thus water intakes type can be seen as a three-dimensional orifice on vertical wall. The Model is shown in Fig. 2.

The main flow area and intake tower are connected by water intakes that is located at $15 \mathrm{~m}$ under water surface. RNG $k-\varepsilon$ turbulence model is introduced in model computation; PISO method is used in pressure-velocity coupling calculation; Body Force Weighted is applied to pressure discrete term.
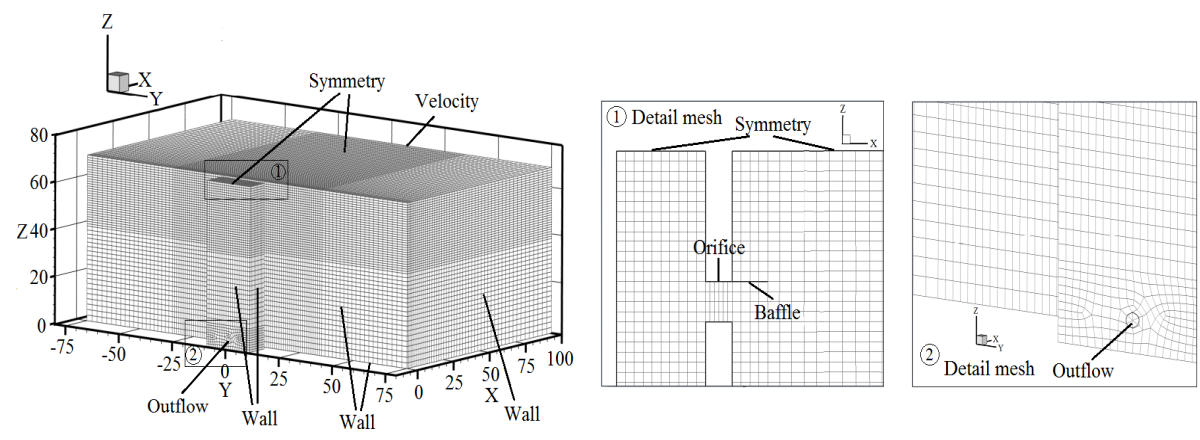

Fig. 2. Model grid schematic diagram for $4 \mathrm{~m}$ baffle (Unit: $\mathrm{m}$ ) 


\subsection{Model parameters}

The operation data of Xi'an Jin-pen Reservoir in August 14, 2012 is taken as the input parameters of CFD model. Then with reservoir bottom as longitudinal coordinate origin, longitudinal water temperature can be roughly divided into three layers, $70 \sim 67.17 \mathrm{~m}$ is epilimnion, the water temperature is fixed as $24.57^{\circ} \mathrm{C}, 67.17 \sim 20.52 \mathrm{~m}$ is thermocline, and from $20.52 \mathrm{~m}$ to the bottom is hypolimnion, the water temperature is fixed as 7.46 .

\section{Results and Discussion}

\subsection{Water flow compared between without baffle and with baffle}

In selective withdrawal, the upper baffle on orifice blocks upper water flow and changes flow velocity. As a result, the thickness of upper withdrawal layer reduces. Fig. 3a presents the streamline diagram of the simulation results without baffle. It suggests that there are withdrawal limits on upper and lower orifice. And the upper and lower withdrawal layer thicknesses, which are $10.7 \mathrm{~m}$ and $12.5 \mathrm{~m}$ respectively, show little difference; Fig. $3 \mathrm{~b}$ displays the streamline diagram of the simulation result of $4 \mathrm{~m}$ horizontal baffle. In this figure, upper withdrawal layer thickness reduces to $6.4 \mathrm{~m}$ blocked by baffle, while the lower thickness show little changes, the value of lower thickness is $12.8 \mathrm{~m}$.

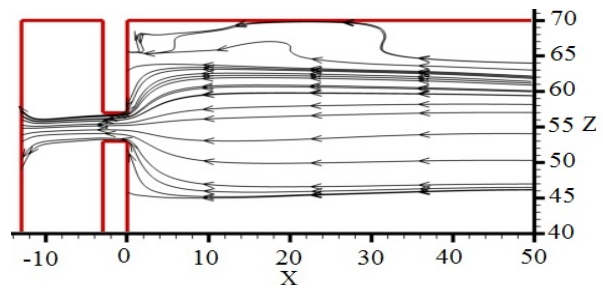

a. No baffle

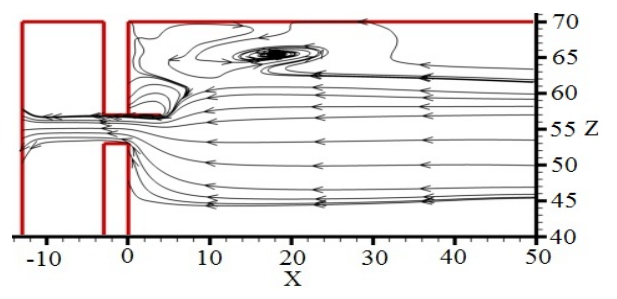

b. $4 \mathrm{~m}$ baffle

Fig. 3. Simulated streamline diagram (Unit $\square \mathrm{m}$ )

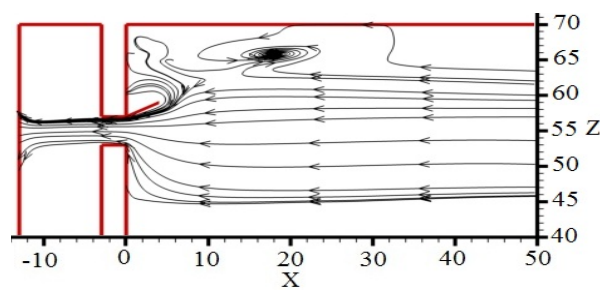

a. $30^{\circ}$

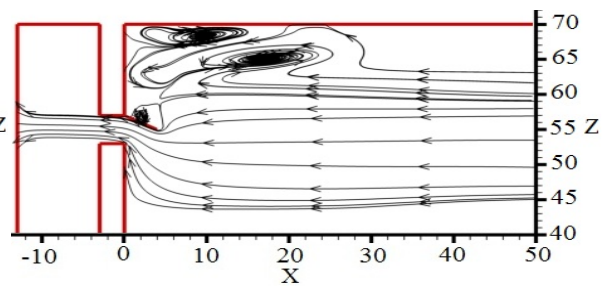

b. $-30^{\circ}$

Fig. 4. The streamline diagrams of $4 \mathrm{~m}$ baffle at two different angles (Unit $\square \mathrm{m}$ ) 


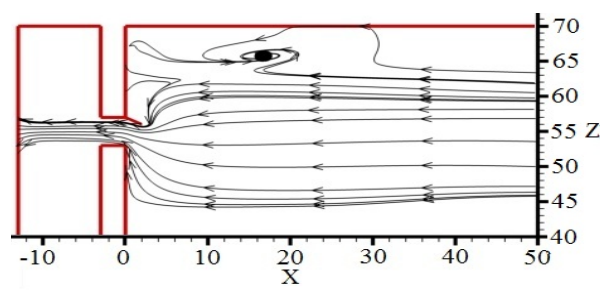

a. $2 \mathrm{~m}$

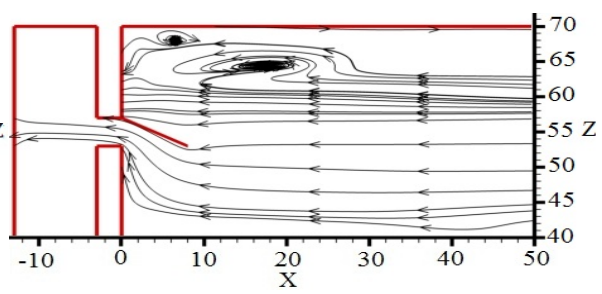

b. $8 \mathrm{~m}$

Fig. 5. The streamline diagrams of two baffles in different lengths at the inclining angle of $30^{\circ}$ (Unit : $\left.\mathrm{m}\right)$

Both of length and inclining angle of baffle can exert different influences on upper and lower withdrawal layer thicknesses and corresponding flow velocity. It can be seen from Fig. 4 and Fig. 5 that the withdrawal layer thickness on lower part of orifice show little fluctuation regardless of how baffle length and inclining angle change, while the that on upper part of orifice are related with the variation of inclining angle.

\subsection{The velocity distribution of withdrawal layer}

Taking $4 \mathrm{~m}$ baffle as an example, the bigger the angle of baffle inclines upward, the smaller the blocking effect to upper water flow is, and the lower the variation of corresponding flow velocity is. In the condition of the same outflow and lower withdrawal layer thickness showing no larger variations, lower water flow velocity increases with the changing of baffle inclining angle. Fig. 6 illustrates the velocity distributions at the distance of $4 \mathrm{~m}, 10 \mathrm{~m}$, and $15 \mathrm{~m}$ away from orifice at three different inclining angles.

In the lower withdraw layer of orifice, the velocity on the same height grows with the increase of downward inclining angle, that is, $-30^{\circ}>0^{\circ}>30^{\circ}>$ no. In addition, the influencing degree reduces with the increase of the horizontal distance from orifice.
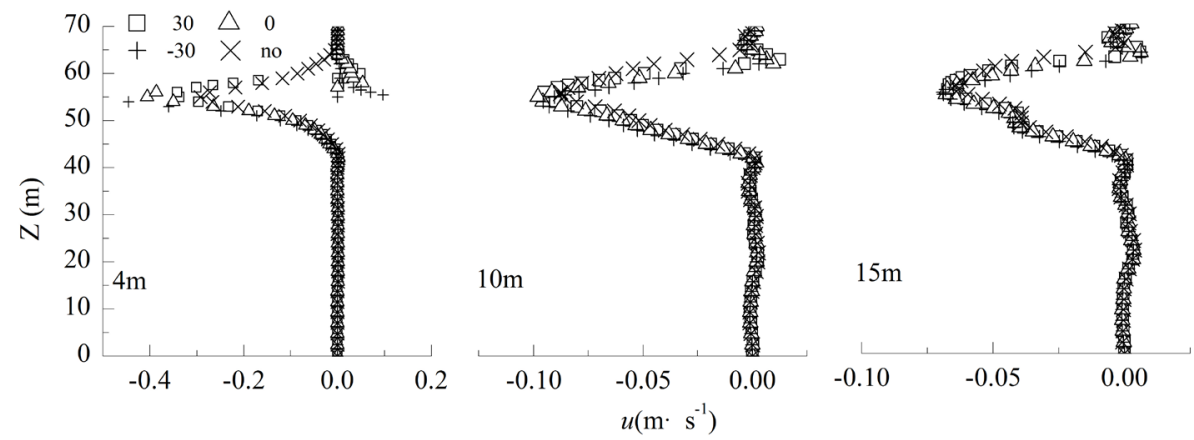

Fig. 6. The velocity distributions of five different sections distanced from the orifice 
It can be seen form Fig. 6 that, on the area above $65.5 \mathrm{~m}$, the flow velocity without baffle shows little differences with that with baffle on arbitrary sections away from orifice. Besides, the baffle at the five inclining angles shows no influences to the flow velocity in this area.

\subsection{Withdrawal layer thickness}

When baffle is not installed, upper and lower withdrawal layer thicknesses are basically in consistence; when baffle is installed, in the principal of taking selective withdrawal boundary layer velocity as 0 , upper withdraw layer thickness reduces, this is because the water flow on the upper part of orifice is blocked (Figure 6). Meanwhile, the blocking degree in different length and different inclining angles of baffle also present differences. The upper and lower withdraw layer thickness that is $10 \mathrm{~m}$ away from orifice are obtained, the detail results are shown in Table 1. Concerning the baffle of $8 \mathrm{~m}$ in Figure 8, although there are left toward water flow velocity on the upper part of orifice, the flow direction is opposite with orifice. Therefore, the withdraw limit of upper withdraw layer of orifice cannot be simply determined by taking velocity as 0 , but must be combined with Figure 5. Corresponding rough ranges of the withdraw layer thickness on the upper part of orifice are listed in the corresponding brackets of Table 1 .

Table 1 indicates that, when baffle is $2 \mathrm{~m}$ long, the withdrawal layer on the upper part of orifice is reduced by $2 \sim 3 \mathrm{~m}$ whether the baffle is inclined upward or downward. When baffle is $4 \mathrm{~m}$ long, upper withdrawal layer thickness exhibits significant reduction at the same inclining angle. When baffle length is $8 \mathrm{~m}$ and inclining angle is upward, the variation amplitude of upper withdrawal layer thickness is smaller comparing with that when baffle is $4 \mathrm{~m}$ long; but when angle inclines downwardly, upper withdrawal layer thickness exhibits significant variations; when inclining angle is -30 $\circ$, upper withdrawal layer thickness reduces to $0 \mathrm{~m}$. This phenomenon means that the water flowing toward orifice is mainly from the lower part of orifice.

It can be observed from Figure 4 and Figure 5 that, no matter how long the baffle is and how inclining angle changes, the withdrawal thickness on the lower part of orifice has not been changed significantly. Table 1 also shows that, comparing with the selective withdrawal without baffle, the biggest variation value of the withdrawal thickness on the lower part of orifice is $1.4 \mathrm{~m}$.

Table 1. The withdrawal layer thickness on $10 \mathrm{~m}$ away from orifice

\begin{tabular}{|c|c|c|c|c|}
\hline Baffle length, inclining angle & $\mathbf{2 ~} \mathbf{~ m}$ & $\mathbf{4 ~ m}$ & $\mathbf{8 ~ \mathbf { ~ m }}$ & $\mathbf{n o}$ \\
\hline \multirow{2}{*}{$30^{\circ}$} & 8.8 & 7.3 & 6.4 & 10.7 \\
\cline { 2 - 5 } & 12.7 & 12.8 & 12.8 & 12.5 \\
\hline \multirow{2}{*}{$0^{\circ}$} & 7.5 & 6.4 & $6.3(5.0)$ & 10.7 \\
\cline { 2 - 5 } & 12.9 & 12.8 & 13.5 & 12.5 \\
\hline \multirow{2}{*}{$-30^{\circ}$} & 7.8 & 6.6 & $6.1(\approx 0.0)$ & 10.7 \\
\cline { 2 - 5 } & 13.0 & 13.6 & 13.9 & 12.5 \\
\hline
\end{tabular}

*The numeral means the upper layer thickness (m); the inclined numeral means the lower layer thickness (m) 


\subsection{The discharge change of upper-lower layer}

The analysis above suggests that the water flow velocity and withdrawal layer thickness on the upper part of orifice are all lower than those on the lower part of orifice in the presence of baffle. According to flow formula $\mathrm{Q}=\mathrm{A} \times \mathrm{v}$. The discharge flow on upper part of the orifice is also smaller than that on the lower part of orifice. Thus the upper and lower flow distribution changes, the detail results are shown in Table 2.

Table 2. The upper and lower flow distribution in $\mathrm{X}$ direction on the area of $1 \mathrm{~m}$ away from baffle

\begin{tabular}{|c|c|c|c|c|}
\hline Baffle length, inclining angle & $\mathbf{2} \mathbf{~ m}$ & $\mathbf{4} \mathbf{~ m}$ & $\mathbf{8} \mathbf{~ m}$ & no \\
\hline \multirow{2}{*}{$30^{\circ}$} & 12.95 & 11.95 & 11.14 & 13.62 \\
\cline { 2 - 5 } & 15.55 & 16.55 & 17.36 & 14.88 \\
\hline \multirow{2}{*}{$0^{\circ}$} & 11.81 & 9.81 & 8.60 & 13.62 \\
\cline { 2 - 5 } & 16.69 & 18.69 & 19.90 & 14.88 \\
\hline \multirow{2}{*}{$-30^{\circ}$} & 9.13 & 5.77 & 5.31 & 13.62 \\
\cline { 2 - 5 } & 19.37 & 22.73 & 23.19 & 14.88 \\
\hline
\end{tabular}

*The numeral means the upper flow $(\mathrm{m} 3 / \mathrm{s})$; the inclined numeral means the lower flow $\left(\mathrm{m}^{3} / \mathrm{s}\right)$

In Table 2, when baffle is with same length, the larger the angle inclines upward, the smaller the changing degree of the flow on the upper and lower part of orifice is, and vice versa. Moreover, this changing degree enlarges with the increase of length; Concerning the baffle with length of $4 \mathrm{~m}$ and $8 \mathrm{~m}$, the upper and lower flow changing degree is very small at the same inclining angle. It should be noted that, when baffle is $8 \mathrm{~m}$ long, there are also flow going through the baffle, although the upper withdrawal layer thickness is close to $0 \mathrm{~m}$ when inclining angle is $-30^{\circ}$. Comparing with the selective withdrawal without baffle, when baffle is $4 \mathrm{~m}$, and $8 \mathrm{~m}$, and inclining angle is $-30^{\circ}$, the upper and lower flow is changed by $8 \mathrm{~m} 3 / \mathrm{s}$ around, which is account for $27.8 \%$ of total flow. Besides, the upper and lower flow distribution ratio is about $1: 4.3$.

It can be seen from Table 2 that, the longer the baffle is, the better the blocking effect of baffle to upper water is. However, since the impact effect of water to baffle show direct ratio with baffle length, the requirement for long baffle strength shall be higher. In summary, the blocking effect of the baffle with $4 \mathrm{~m}$ in length to the water flow on the upper part of orifice is apparently better than that of $2 \mathrm{~m}$. Moreover, comparing with the baffle with $8 \mathrm{~m}$ in length, the baffle with $4 \mathrm{~m}$ in length also displays the highest cost performances due to the requirements on material. Although when baffle is $8 \mathrm{~m}$ in length and inclining angle is $-30^{\circ}$, the withdraw layer thickness is about $0 \mathrm{~m}$, the flow that go through the orifice show insignificant differences with that when baffle length is $4 \mathrm{~m}$.

Data indicates that when the water quality on the lower part of orifice is obviously better than that in upper part, the upper water can be resisted by installing baffle on the upper part of orifice to obtain better raw water. Comparing with existing facilities for selective withdraw water, this device is provided with simple structure and con- 
venient operation. It can reduce the time and difficulties of underwater construction. Moreover, its project expenditure is lower, which probably include stainless steel for the baffle and other replacement, its simple manufacture and installation on the water intake tower. The material and manufacture cost of a suit of baffle, two baffle and its replacement, is simply estimated roughly $\$ 10,000$; the installation charge can be discussed based on different orifice: for upper orifice, the baffle can be easy installed when orifice bare in the atmosphere, the cost maybe $\$ 2,000$; for the middle and lower orifice, the installation must be in underwater by diver, so the cost may be expensive, about $\$ 20,000$ per orifice to the maximum extent. Therefore, the construction total cost need about $\$ 72,000$.

\section{Conclusion}

Water intake tower with fixed water intakes can not flexibly adjust the withdrawal limit in longitudinal selective withdraw. Moreover, the renovation cost of existing technologies is very high. Therefore, the authors install baffles on the upper and lower part of orifice. By opening and rotating the upper (lower) baffle, water flow can be blocked and the blocking effect can be adjusted by changing baffle length and inclining angle. This method can solve the problem of the poorer water quality leaded by partial harmful water quality to some extent. Moreover, it strengthens the selectivity of selective water intake tower and improves water quality.

The CFD model of selective water intake tower with baffle is established for simulation. The results show that, with $4 \mathrm{~m}$ baffle as limit, upper withdrawal layer thickness shows relatively little variations with the change of inclining angle on the $2 \mathrm{~m}$ baffle length; while the flow distribution ratio on the upper and lower part of orifice are enlarged with the increase of baffle length and downward inclining angle. When baffle is $4 \mathrm{~m}$ and $8 \mathrm{~m}$ in length respectively, the upper withdrawal layer thickness reduces with the increase of baffle length and downward inclining angle. Besides, when baffle is $8 \mathrm{~m}$ and inclining angle is $-30^{\circ}$, upper withdrawal layer thickness is almost close to $0 \mathrm{~m}$; in addition, with the same length in this baffle length range, the larger the inclining angle is, the bigger upper and lower flow distribution ratio is. The biggest flow distribution ratio reaches to 1:4.3; flow distribution shows little variations with the increase of length at the same angle. But the increase of baffle length requires better materials.

The analyzing results of withdrawal layer thickness, flow distribution ratio and material requirements show that $4 \mathrm{~m}$ baffle is the most favourable one. When the water on the upper part of orifice is polluted, the upper water can be blocked by baffle. Thus, the raw water quality of water plant is improved. Furthermore, comparing with other measures mentioned in this study, the capital construction cost reduces due to the simple structure of the device. 


\section{Acknowledgements}

The authors would like to acknowledge the financial support from the National Natural Science Foundation of China (51778523) .

\section{References}

[1] Montgomery S., Lucotte M., \& Rheault I. (2000). Temporal and spatial influences of flooding on dissolved mercury in boreal reservoirs: Science of the total environment, 260(1): 147-157. https://doi.org/10.1016/S0048-9697(00)00559-3

[2] Little J.C., \& Mcginnis D.F. (2001). Hypolimnetic oxygenation: predicting performance using a discrete-bubble mode: Water Science \& Technology: Water Supply, 1(4): 185-191.

[3] Fer I., Lemmin U., \& Thorpe S. A. (2002). Observations of mixing near the sides of a deep lake in winter: Limnology \& oceanography, 47(2): 535-544. https://doi.org/10.4319/1o.200 2.47.2.0535

[4] Brzáková M., Hejzlar J., \& Nedoma J. (2003). Phosphorus uptake by suspended and settling seston in a stratified reservoir: Hydrobiologia, 504(1): 39-49. https://doi.org/10.1023/ B:HYDR.0000008506.29287.11

[5] González E. J., Ortaz M., Peñaherrera C., \& de Infante A. (2004). Physical and chemical features of a tropical hypertrophic reservoir permanently stratified: Hydrobiologia, 522(1): 301-310. https://doi.org/10.1023/B:HYDR.0000029983.53568.d2

[6] Branco C. W., Kozlowsky - Suzuki B., Sousa-Filho I. F., Guarino A. W., \& Rocha R. J. (2009). Impact of climate on the vertical water column structure of Lajes reservoir (Brazil): a tropical reservoir case: Lakes \& Reservoirs: Research \& Management, 14(3): 175191. https://doi.org/10.1111/j.1440-1770.2009.00403.x

[7] Gantzer P. A., Bryant L. D., \& Little J. C. (2009). Effect of hypolimnetic oxygenation on oxygen depletion rates in two water-supply reservoirs: Water research, 43(6): 1700-1710. https://doi.org/10.1016/j.watres.2008.12.053

[8] Palmer C. M. (2007). A composite rating of algae tolerating organic pollution: Journal of Phycology, 5(1): 78-82. https://doi.org/10.1111/j.1529-8817.1969.tb02581.x

[9] Herrero R., Lodeiro P., Rojo R., Ciorba A., Rodríguez P., \& Sastre de Vicente M. E. (2008). The efficiency of the red alga Mastocarpus stellatus for remediation of cadmium pollution: Bioresource technology, 99(10): 4138-4146. https://doi.org/10.1016/j.biortech.2 $\underline{007.08 .065}$

[10] Xia P. H., Zhang M. S., \&Li C. X. (2010). Analysis on the eutrophication and algae blooms of Hongfeng Lake reservoir in Guizhou: Meteorological \& Environmental Research, 1(12): 96-98.

[11] Farrow D. E., \& Hocking G. C. (2006). A numerical model for withdrawal from a twolayer fluid: Journal of Fluid Mechanics, 549(1): 141-157. https://doi.org/10.1017/S002211 2005007561

[12] Anohin V. V., Imberger J., Romero J. R., \& Ivey G. N. (2006). Effect of long internal waves on the quality of water withdrawn from a stratified reservoir: Journal of Hydraulic Engineering, 132(11): 1134-1145. https://doi.org/10.1061/(ASCE)0733-9429(2006)132:1 1(1134)

[13] Böhlke J. K., Verstraeten I. M., \& Kraemer T. F. (2007). Effects of surface-water irrigation on sources, fluxes, and residence times of water, nitrate, and uranium in an alluvial aqui- 
fer: Applied geochemistry, 22(1): 152-174. https://doi.org/10.1016/j.apgeochem.2006.08.0 19

[14] Preece R. M., \& Jones H. A. (2002). The effect of Keepit Dam on the temperature regime of the Namoi River, Australia: River Research \& Applications, 18(4): 397-414. https://doi.org/10.1002/rra.686

[15] Shammaa Y., \& Zhu D. Z. (2009). Experimental study on selective withdrawal in a twolayer reservoir using a temperature-control curtain: Journal of Hydraulic Engineering, 136(4): 234-246. https://doi.org/10.1061/(ASCE)HY.1943-7900.0000165

[16] Gelda R. K., \& Effler S. W. (2007). Simulation of operations and water quality performance of reservoir multilevel intake configurations: Journal of Water Resources Planning \& Management, 133(1): 78-86. https://doi.org/10.1061/(ASCE)0733-9496(2007)133:1(78)

[17] Asaeda T., Priyantha D. G., Saitoh S., \& Gotoh K. (1996). A new technique for controlling algal blooms in the withdrawal zone of reservoirs using vertical curtains: Ecological Engineering, 7(2): 95-104. https://doi.org/10.1016/0925-8574(96)00002-X

[18] Asaeda T., Pham H. S., Nimal - Priyantha D. G., Manatunge J., \& Hocking G. C. (2001). Control of algal blooms in reservoirs with a curtain: a numerical analysis: Ecological Engineering, 16(3): 395-404. https://doi.org/10.1016/S0925-8574(00)00123-3

[19] Khangaonkar T., Yang Z., Paik J., \& Sotiropoulos F. (2008). Simulation of hydrodynamics at stratified reservoirs using a staged modeling approach: Journal of Coastal Research, 52: 79-86. https://doi.org/10.2112/1551-5036-52.sp1.79

[20] Savage B. M., \& Johnson M. C. (2001). Flow over ogee spillway: Physical and numerical model case study: Journal of Hydraulic Engineering, 127(8): 640-649. https://doi.org/10.1061/(ASCE)0733-9429(2001)127:8(640)

[21] Georgoulas A.N., Angelidis P.B., Panagiotidis T.G., \& Kotsovinos N.E. (2010). 3D numerical modeling of turbidity currents: Environmental Fluid Mechanics., 10(6): 603-635. https://doi.org/10.1007/s10652-010-9182-z

\section{Authors}

Lu Jinsuo is a professor at Xian University of Architecture \& Technology (XAUAT). He holds a Ph.D. in engineering. He was a full-time assistant engineer in China Northwest Municipal Engineering Design institute Co., Ltd. He headed 2 research projects from National Science Foundation of China.

Zhang Wei, Wang Dengyu, and Wang Xiaoyi are with Xi'an University of Architecture and Technology, Xi'an, China.

Article submitted 11 February 2018. Final acceptance 05 March 2018. Final version published as submitted by the authors. 